\title{
Long non-coding RNA zinc finger antisense 1 functions as an oncogene in acute promyelocytic leukemia cells
}

\author{
LIFANG SU ${ }^{1}$, HONGWEI KONG ${ }^{2}$, FENZHI WU ${ }^{2}$, HONGJIAO $\mathrm{LV}^{2}$, WENPING WU ${ }^{2}$, \\ GANG WANG $^{2}$, XUEFEN YAN $^{2}$, JIAHENG WANG $^{2}$ and QIANG FANG ${ }^{3}$ \\ ${ }^{1}$ School of Medicine, Zhejiang University, Hangzhou, Zhejiang 310058; ${ }^{2}$ Department of Hematopathology, \\ Quzhou People's Hospital, Quzhou, Zhejiang 324000; ${ }^{3}$ Intensive Care Unit, The First Affiliated Hospital, \\ School of Medicine, Zhejiang University, Hangzhou, Zhejiang 310003, P.R. China
}

Received August 30, 2016; Accepted January 3, 2019

DOI: $10.3892 / 01.2019 .11014$

\begin{abstract}
Despite progress in the diagnosis and treatment of acute promyelocytic leukemia (APL), its prognosis remains poor. Multiple studies have shown that long non-coding RNAs (lncRNAs) are involved in carcinogenesis and metastasis. The present study assessed the function of the IncRNA zinc finger antisense 1 (ZFAS1) in APL. In a cohort of 33 patients, ZFAS1 was significantly overexpressed compared with the level in healthy controls. To investigate the specific mechanisms of this upregulation, in vitro studies showed that silencing of ZFAS1 by small interfering RNA significantly inhibited cell proliferation in APL cells. Moreover, downregulation of ZFAS1 increased cellular apoptosis, decreased expression of B-cell lymphoma-2 and of induced myeloid leukemia cell differentiation protein Mcl-1, increased the expression of apoptosis regulator BAX and promoted the release of cytochrome $c$ and Diablo homolog mitochondrial into the cytoplasm. In conclusion, these data indicate that ZFAS1 may serve as an oncogene in APL and may thus be a useful target for future clinical management.
\end{abstract}

\section{Introduction}

Acute promyelocytic leukemia (APL) is characterized by a balanced reciprocal translocation between chromosomes 15 and 17, causing a fusion between promyelocytic leukemia (PML) and retinoic acid receptor $\alpha$ (1). Despite recent progress in the diagnosis and treatment of APL, its prognosis remains poor (2). Therefore, novel prognostic markers that are associated with APL progression would be of great clinical relevance.

Long non-coding RNAs (lncRNAs) refer to non-protein coding transcripts of $>200$ nucleotides in length, which are

Correspondence to: Dr Qiang Fang, Intensive Care Unit, The First Affiliated Hospital, School of Medicine, Zhejiang University, 79 Qingchun Road, Hangzhou, Zhejiang 310003, P.R. China E-mail: qfang841@163.com

Key words: acute promyelocytic leukemia, long non-coding RNA, zinc finger antisense 1, apoptosis, B-cell lymphoma-2 involved in a wide range of biological behaviors, including epigenetic regulation, chromatin modification, transcription and post-transcriptional processing (3-5). Increasing evidence has confirmed the role of IncRNAs in carcinogenesis, acting as proto-oncogenes or tumor suppressor genes $(6,7)$. For example, lncRNA growth arrest-specific 5 and maternally expressed 3 act as tumor suppressor genes, and metastasis associated lung adenocarcinoma transcript 1 and HOX transcript antisense RNA function as oncogenes (8-11). The newly identified lncRNA zinc finger antisense 1 (ZFAS1) is highly expressed in mammary glands and functions as a tumor suppressor gene in human breast cancer (12). Moreover, ZFAS1 is upregulated in colorectal cancer tissue and is an oncogene in hepatocellular carcinoma $(13,14)$. To date, there have been several studies on the function of IncRNAs in APL. For example, IncRNA nuclear paraspeckle assembly transcript 1 (NEAT1) is involved in myeloid differentiation, which can be abrogated following the inhibition of NEAT1 (15). Moreover, lncRNA Pvt1 oncogene (PVT1) was found to be overexpressed in APL, and knockdown of PVT1 led to suppression of MYC proto-oncogene bHLH transcription factor expression and cell viability (16). These findings implicated the potential role of lncRNAs in the development of APL. However, to the best of our knowledge, the role of ZFAS1 in APL has not yet been described.

The present study aimed to characterize the role and regulation of ZFAS1 in APL. This is, to the best of our knowledge, the first study to demonstrate the potential function of ZFAS1 in APL. The findings from this study may provide novel insights into the mechanisms of APL progression.

\section{Materials and methods}

Clinical samples. A total of 59 peripheral blood samples were collected with informed consent. This included 33 samples from patients with APL (mean age \pm standard deviation, $62.4 \pm 4.8$ years) collected at the time of diagnosis and 26 samples from healthy donors (mean age, 47 years). The peripheral blood mononuclear cells of APL samples were isolated using Ficoll-Hypaque gradient centrifugation method (d=1.077 g/mol; Sigma-Aldrich; Merck KGaA, Darmstadt, Germany) (17). Regarding the isolation of the granulocyte fraction, contaminating erythrocytes were hemolysed with 
cold ammonium chloride solution $(250 \mathrm{mM})$. The ammonium chloride solution was added directly into the peripheral blood mononuclear cell fraction and subsequent granulocytes were collected and washed once with PBS as described earlier (18). The granulocyte was diluted in PBS and collected by centrifugation at $300 \times \mathrm{g}$ for $15 \mathrm{~min}$ at $4^{\circ} \mathrm{C}$ and subsequently, the pellets were stored at $80^{\circ} \mathrm{C}$. Patient characteristics are described in Table I. All of the procedures were conducted according to the guidelines of the Medical Ethics Committees of the Health Bureau of the Zhejiang Province of China, and ethical approval was obtained from the Ethics Committee of the Medical School of Zhejiang University (Hangzhou, China).

Cell culture and transfection. The NB4 and NB4-all-trans retinoic acid-resistant (NB4-R-ATRA) cell lines were generous gifts provided by Dr Jianguo Chen (Sun Yat-Sen Hospital, Shanghai, China). The HL-60 cell line was purchased from the Cell Bank of Shanghai Institute of Biological Sciences (www.cellbank.org.cn; Chinese Academy of Sciences, Shanghai, China). All cells were cultured in RPMI-1640 medium supplemented with $10 \%$ (v/v) fetal calf serum, $1 \%$ (v/v) antibiotic-antimycotic solution and $2 \mathrm{mM}$ L-glutamine (all Gibco; Thermo Fisher Scientific, Inc., Waltham, MA, USA) in a humidified atmosphere at $37^{\circ} \mathrm{C}$ and with $5 \% \mathrm{CO}_{2}$.

Chemicals and reagents. ATRA was purchased from Sigma-Aldrich; Merck KGaA, and dissolved in EtOH at the stock concentration of $20 \mathrm{mM}$. Cells were treated with $1 \mu \mathrm{M}$ ATRA for $24 \mathrm{~h}$. All other chemical reagents were also obtained from Sigma-Aldrich; Merck KGaA.

$R N A$ extraction and reverse transcription-quantitative polymerase chain reaction ( $R T-q P C R)$. Total cellular RNA was purified using TRIzol ${ }^{\circledR}$ (Thermo Fisher Scientific, Inc.) according to the manufacturer's protocols. The expression levels of ZFAS1 were detected by RT-qPCR using a SYBR ExScript RT-PCR kit (Takara Biotechnology Co., Ltd., Dalian, China), performed in an Applied Biosystems 7500 PCR system (Thermo Fisher Scientific, Inc.). qPCR was performed with the following cycling conditions: 40 cycles of denaturation at $95^{\circ} \mathrm{C}$ for $30 \mathrm{sec}$, annealing at $59^{\circ} \mathrm{C}$ for $30 \mathrm{sec}$ and extension at $72^{\circ} \mathrm{C}$ for $15 \mathrm{sec}$. Samples were amplified in triplicate, and data were normalized to the expression of glyceraldehyde 3-phosphate dehydrogenase (GAPDH). The primer sequences were as follows: GAPDH forward, 5'-AGATGTTCCAATATGATTCC-3' and reverse, 5'-TGGACTCCACGACGTACTCAG-3' and ZFAS1 forward, 5-ACGTGCAGACATCTACAACCT-3' and reverse, 5-TAC TTCCAACACCCGCAT-3'. The relative mRNA expressions of target genes were calculated using the $2^{-\Delta \Delta \mathrm{Cq}}$ method (19).

RNA interference. Two small interfering (si)RNA constructs against ZFAS1 were generated. ZFAS1-1 siRNA (5'-CTGGCT GAACCAGTTCCACAAGGTT-3'), ZFAS1-2 siRNA (5'-TAC TTCTCCTAGTTGCAGTCAGG-3') and the scramble siRNA (5'-ACGTGACACGTTCGGAGAATT-3') were purchased from Shanghai Sangon Co., Ltd. (Shanghai, China). NB4 cells were transfected with $20 \mu \mathrm{M}$ siRNAs using the Neon Transfection system (Thermo Fisher Scientific, Inc.) according to the manufacturer's protocol. Following $24 \mathrm{~h}$ transfection, ZFAS1 level was determined by RT-qPCR.
Cell proliferation assay. Cell proliferation was measured using Cell Counting Kit-8 (CCK-8; Promega Corporation, Madison, WI, USA) according to the manufacturer's protocol. Briefly, cells were plated at a density of $1 \times 10^{4}$ cells/well in 96-well plates and cultured in RPMI-1640 medium. The CCK-8 reagent $(10 \mu \mathrm{l})$ was added to the wells at the end of the experiment. Following incubation at $37^{\circ} \mathrm{C}$ for $2 \mathrm{~h}$, the absorbance in each well was determined using a microplate reader at $450 \mathrm{~nm}$.

Cytosolic fraction isolation. To isolate the cytosolic fraction, cells were washed with ice-cold PBS. The cells were lysed using the Cell Lysis and Mitochondria Intact buffer (Beyotime Institute of Biotechnology, Haimen, China) on ice for $5 \mathrm{~min}$, and the cell suspension was centrifuged at $500 \mathrm{x} \mathrm{g}$ for $5 \mathrm{~min}$ at $4^{\circ} \mathrm{C}$. The supernatant was removed and stored at $-20^{\circ} \mathrm{C}$ as the cytosolic fraction. This was subsequently separated by $12 \%$ SDS-PAGE and the proteins were detected by the western blot assay.

Western blot assay. The cells were lysed using radioimmunoprecipitation assay buffer on ice for $30 \mathrm{~min}$ and the protein concentration was determined with the Bradford assay (both Beyotime Institute of Biotechnology). The proteins $(25 \mu \mathrm{g})$ were separated by $12 \%$ SDS-PAGE and transferred onto polyvinylidene fluoride membranes (EMD Millipore, Billerica, MA, USA). The membranes were blocked with 5\% skimmed milk for $1 \mathrm{~h}$ at room temperature, and incubated at $4^{\circ} \mathrm{C}$ overnight with primary antibodies diluted at 1:1,000 against Mcl-1 (cat. no. ab32087; Abcam, Cambridge, MA, USA), caspase-9 (cat. no. 9502), cleaved caspase-9 (cat. no. 9505), caspase-3 (cat. no. 9662), cleaved caspase-3 (cat. no. 9661), caspase-8 (cat. no. 9746), Bcl-2 (cat. no. 4223), cytochrome $c$ (cat. no. 12963), Smac/DIABLO (cat. no. 15108), GAPDH (cat. no. 5174), PARP (cat. no. 9532), XIAP (cat. no. 2045) and BAX (cat. no. 5023) (all Cell Signaling Technology, Inc., Danvers, MA, USA). Membranes were subsequently incubated with the goat anti-mouse (cat. no. 31430) or goat anti-rabbit (cat. no. 31460) horseradish peroxidase-conjugated secondary antibodies (1:2,000; both from Thermo Fisher Scientific, Inc.) for $1 \mathrm{~h}$ at room temperature. Enhanced chemiluminescence reagent (Thermo Fisher Scientific, Inc.) was used to detect the signal on the membrane with a Bio Image Intelligent Quantifier 1D (Bio Image Systems, Inc., Jackson, MI, USA). Densitometric analysis was performed with Quantity One software (version 4.6.8; Bio-Rad Laboratories, Inc., Hercules, CA, USA).

Flow cytometry analysis. Cells $\left(2 \times 10^{5}\right)$ were washed twice PBS and then fixed with $70 \%$ ethanol at room temperature for $30 \mathrm{~min}$. Next, the cell cycle distribution was analyzed by flow cytometry (FACSCalibur; Becton, Dickinson and Company, Franklin, Lakes, NJ, USA) using DNA staining with propidium iodide ( $1 \mathrm{mg} / \mathrm{ml}$; Sigma-Aldrich; Merck KGaA) and Annexin $\mathrm{V}$ in PBS. The cells undergoing apoptosis were Annexin V-FITC-positive and PI-negative. Data analysis was performed using FlowJo version 8.8.7 software (Tree Star, Inc., Ashland, OR, USA).

Statistical analysis. Differences between two groups were estimated using Student's t-test with Prism version 5.0 
Table I. Clinical characteristics of patients with acute promyelocytic leukemia $(n=33)$.

\begin{tabular}{lrc}
\hline Characteristic & $\mathrm{n}$ & $\%$ \\
\hline Cytogenetics t(15;17) & 33 & 100.0 \\
Age, years & & \\
$10-20$ & 6 & 18.2 \\
$20-30$ & 17 & 51.5 \\
$30-40$ & 9 & 27.3 \\
$40-50$ & 1 & 3.0 \\
Sex & & \\
Male & 20 & 60.6 \\
Female & 13 & 39.4 \\
WBC count $\left(\mathrm{x} 10^{9}\right)$ & & \\
$<10$ & 14 & 42.4 \\
$10-50$ & 10 & 30.3 \\
$>50$ & 4 & 12.1 \\
N/A & 5 & 15.2 \\
Percentage of PB blasts & & \\
$<80$ & 16 & 48.5 \\
$\geq 80$ & 9 & 27.3 \\
N/A & 8 & 24.2 \\
\hline
\end{tabular}

WBC, white blood cell; PB, peripheral blood; N/A, not available.

(GraphPad Software, Inc., La Jolla, CA, USA). Differences among three groups were analyzed using one-way analysis of variance followed by Tukey's test post-hoc with SPSS (version 17; SPSS, Inc., Chicago, IL, USA). P $<0.05$ was considered to indicate a statistically significant difference.

\section{Results}

ZFAS1 is upregulated in patients with APL. To investigate whether ZFAS1 is involved in the development of APL, the ZFAS1 expression levels in 33 APL patient samples (Table I) were first compared with the levels in 26 healthy donor samples. As shown in Fig. 1, the ZFAS1 expression level was significantly increased in APL samples compared with that in healthy controls. This result suggests that ZFAS1 upregulation may have a positive association with the development of APL.

ATRA treatment results in the downregulation of ZFAS1. NB4 cells has been widely accepted as a model of myeloid maturation in which ATRA treatment leads to a proliferation block at the $\mathrm{G}_{1}$ phase and terminates the differentiation of myeloid cells (20-22). Therefore, the present study investigated whether ATRA treatment affects ZFAS1 expression in NB4 cells. As shown in Fig. 2A, ZFAS1 expression levels in NB4 cells decreased following treatment with ATRA $(1 \mu \mathrm{M})$. At the same time, there was little ZFAS1 downregulation found in the ATRA-resistant cell line, therefore excluding the possibility of non-specific stress responses to ATRA treatment (Fig. 2B). These data suggest that ZFAS1 may be involved in the proliferation of NB4 cells.

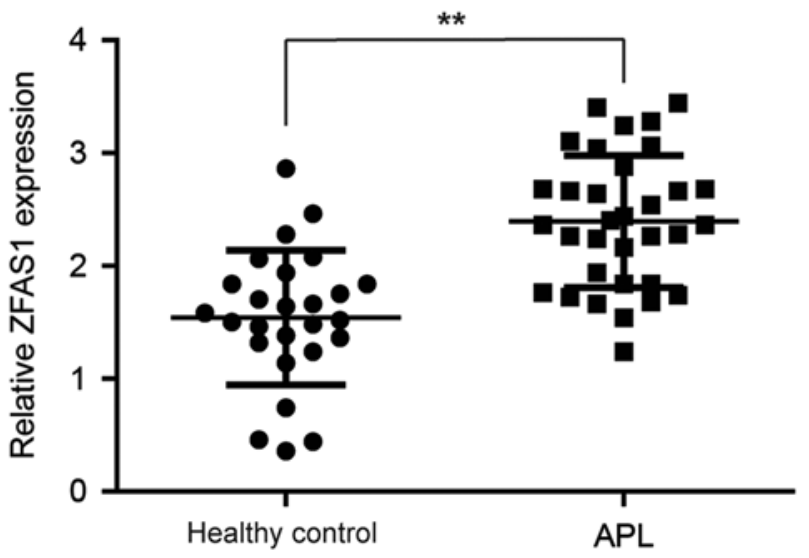

Figure 1. ZFAS1 is highly expressed in APL patients. The levels of ZFAS1 in APL patient samples $(n=33)$ were compared with granulocytes from healthy controls $(n=26)$. ZFAS1 expression was quantified by reverse transcription-quantitative polymerase chain reaction and normalized to the glyceraldehyde 3-phosphate dehydrogenase gene. The expression of ZFAS1 relative to that in healthy controls was calculated using the $2^{-\Delta \Delta C q}$ method. ${ }^{* *} \mathrm{P}<0.01$ (t-test). ZFAS1, long non-coding RNA zinc finger antisense 1; APL, acute promyelocytic leukemia.

Downregulation of ZFAS1 decreases the proliferation of APL cells. To further dissect the function of ZFAS1 in cellular proliferation, two ZFAS1-specific siRNAs were used to repress the expression of ZFAS1 in two APL cell lines, NB4 and HL-60 (Fig. 3A). As shown in Fig. 3B, APL cells transfected with ZFAS1 siRNAs exhibited a lower proliferation rate than the control group. These data further confirmed that ZFAS1 is involved in the proliferation of APL cells.

ZFAS1 regulates APL cell apoptosis through the intrinsic apoptotic pathway. To investigate whether ZFAS1 affects the apoptosis of APL cells, Annexin V/PI staining and flow cytometry analysis were employed. As shown in Fig. 4A, silencing of ZFAS1 markedly promoted the apoptosis of the APL cells. There are two major pathways that lead to apoptosis: The extrinsic pathway, also known as the death receptor signaling pathway, and the intrinsic pathway, also known as the mitochondrial pathway. Caspases are a group of cysteine proteases that are vital regulators of apoptosis. The extrinsic and intrinsic pathways are initiated by caspase- 8 and caspase- 9 , respectively, leading to the activation of caspase-3 (23). To further investigate the potential role of ZFAS1 in APL cell apoptosis in the present study, a western blot assay was performed to detect caspase-3, caspase- 8 and caspase- 9 levels. When ZFAS1 was silenced, cleaved caspase-9, caspase-3 and PARP were increased. At the same time, cleaved caspase- 8 was not significantly affected (Fig. 4B and C). These data suggested that ZFAS1 affects apoptosis via the intrinsic pathway.

ZFASI affects the expression of the Bcl-2 family proteins in $A P L$ cells. The intrinsic pathway is mainly regulated by the $\mathrm{Bcl}-2$ protein family. Therefore, levels of Bcl-2 family proteins were investigated by western blotting. As shown in Fig. 5A, Bcl-2 and Mcl-1 expression levels were decreased, while the expression level of XIAP was not significantly affected following the silencing of ZFAS1. Additionally, Bax expression and release of cytochrome $c$ and Smac/DIABLO were 
A

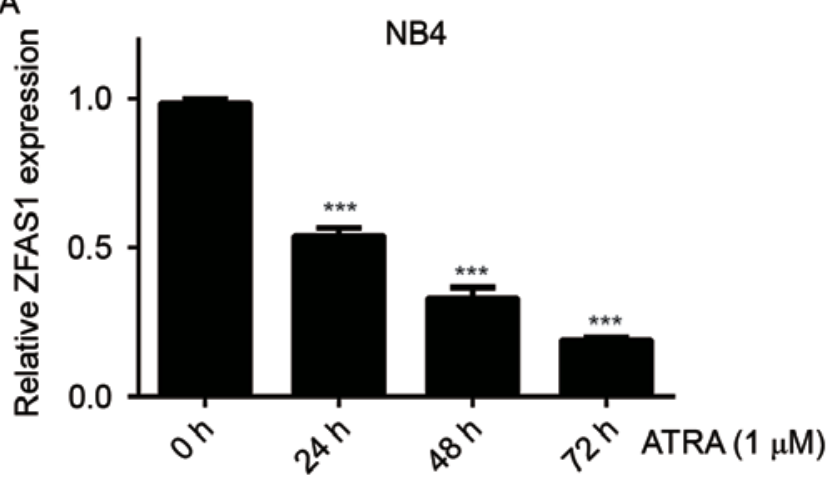

B

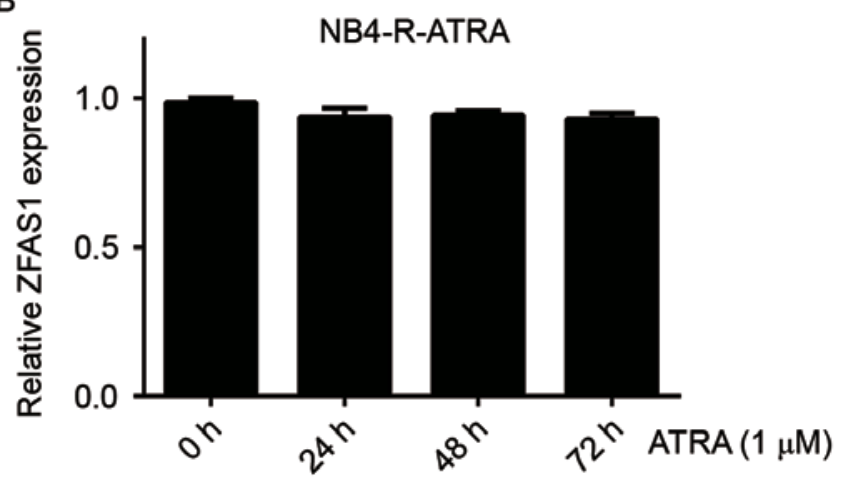

Figure 2. ZFAS1 was significantly decreased in NB4 cells treated with ATRA. (A) NB4 and (B) NB4-R-ATRA cells were treated with $1 \mu$ M ATRA for the indicated times, and ZFAS1 expression was measured by reverse transcription-quantitative polymerase chain reaction. Each panel shows the mean \pm standard deviation of a representative experiment performed in triplicate. ${ }^{* * *} \mathrm{P}<0.001$. ZFAS1, long non-coding RNA zinc finger antisense 1 ; NB4-R-ATRA, NB4-all-trans retinoic acid-resistant.

A
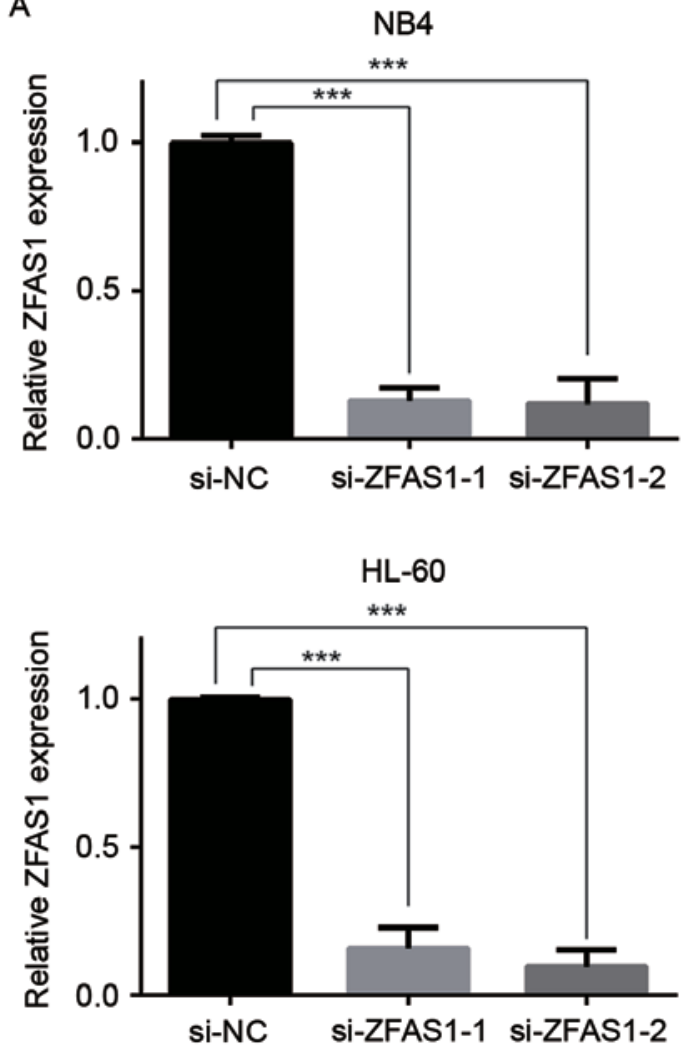

B
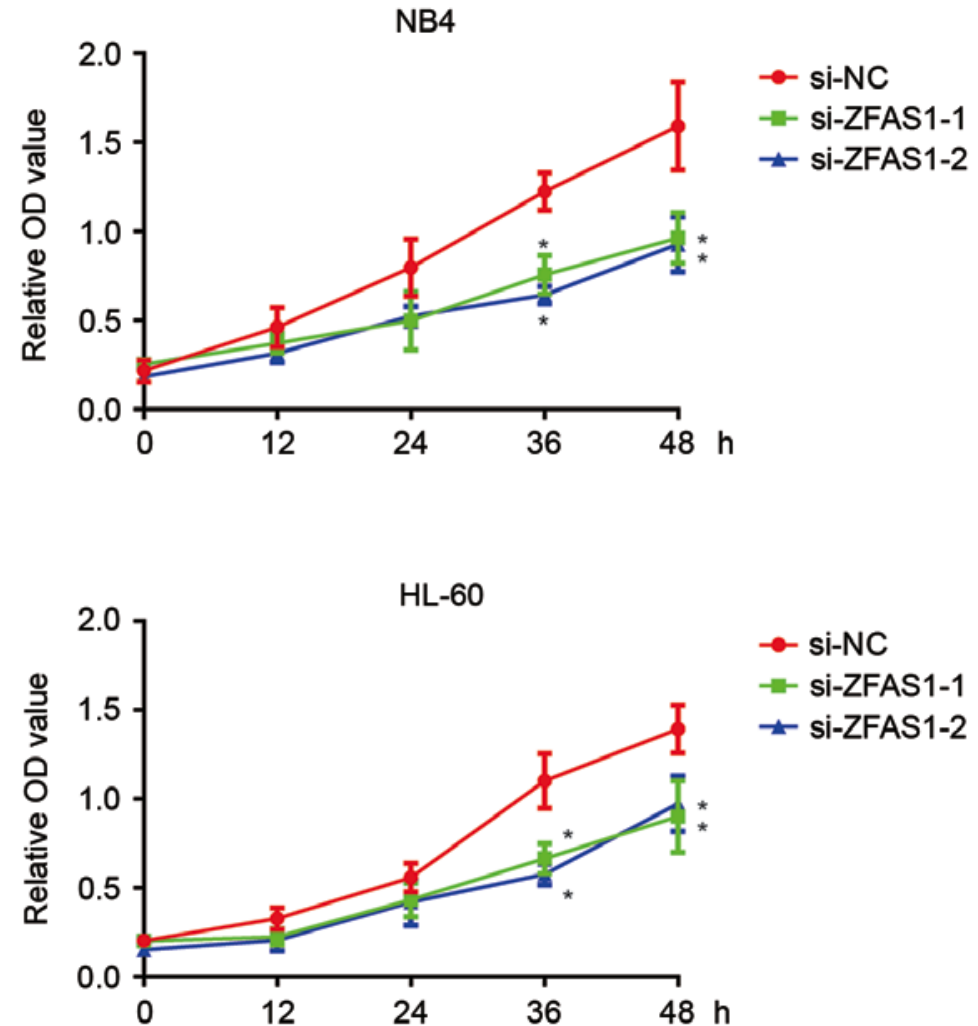

Figure 3. Silencing of ZFAS1 attenuates the proliferation of APL cells. (A) A reverse transcription-quantitative polymerase chain reaction analysis showed that the ZFAS1 expression level was significantly repressed in APL cells transfected with two siRNAs against ZFAS1 (si-ZFAS1-1 and si-ZFAS1-2) compared with that in cells transfected with si-NC. (B) APL cells were transfected with siRNAs against ZFAS1 (si-ZFAS1-1 and si-ZFAS1-2) or si-NC for the indicated times. Cell proliferation was determined using a Cell Counting Kit- 8 assay. The data represent the results of three independent experiments and are presented as the mean \pm standard deviation $(\mathrm{n}=3)$. ${ }^{*} \mathrm{P}<0.05$ and $^{* * * *} \mathrm{P}<0.001$. si-, small interfering; NC, negative control; OD, optical density; ZFAS1, long non-coding RNA zinc finger antisense 1; APL, acute promyelocytic leukemia.

increased in the cytosolic fraction (Fig. 5B). Based on these results, ZFAS1 regulates the intrinsic pathway through the modulation of Bcl-2 family proteins.

\section{Discussion}

APL is a unique form of acute myeloid leukemia (AML) caused by an arrest in granulocyte differentiation during the promyelocytic stage (24). Although clinical advances in AML have been achieved, its prognosis remains quite poor. Therefore, novel approaches are required to target AML. Increasing evidence indicates that IncRNAs are involved in a variety of biological processes, including cell proliferation, survival and differentiation $(4,6)$. In light of the potential value of IncRNAs as biomarkers and therapeutic targets, the present study sought to investigate an lncRNA involved in APL. 
A

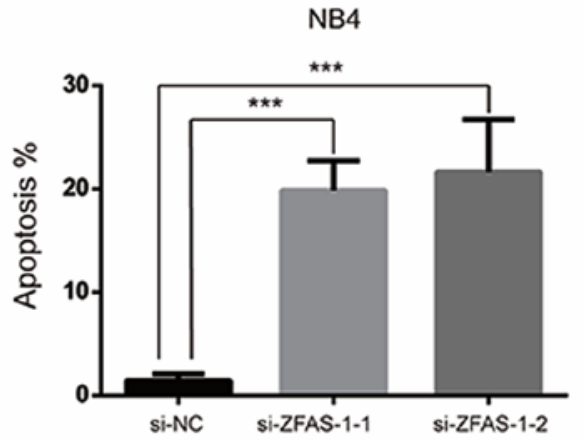

$\mathrm{HL}-60$

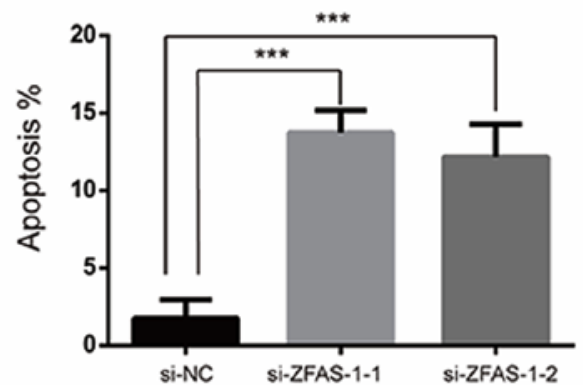

B

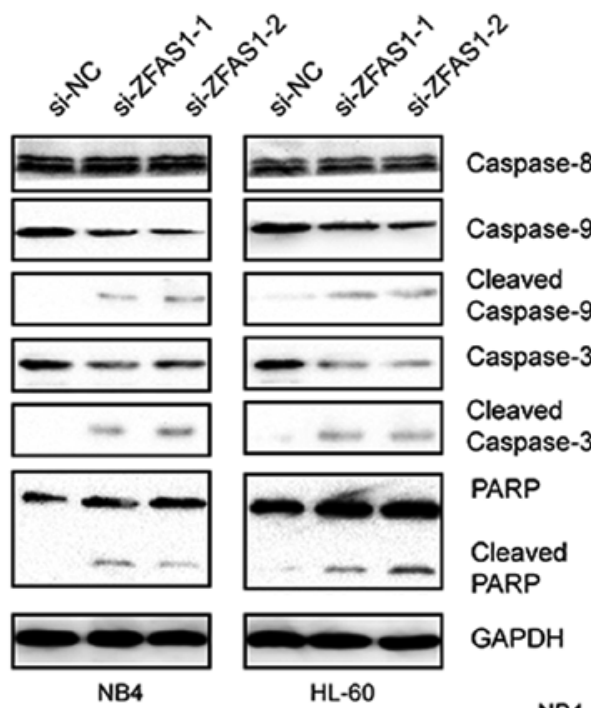

C
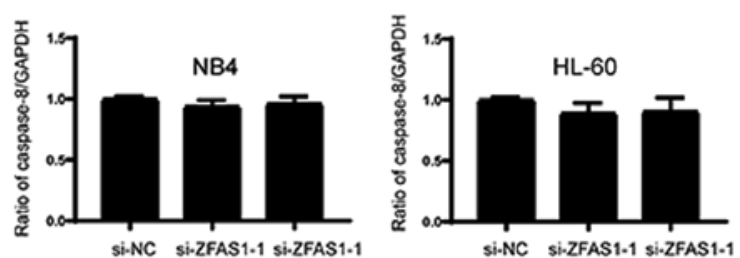

$\mathrm{HL}-60$

NB4
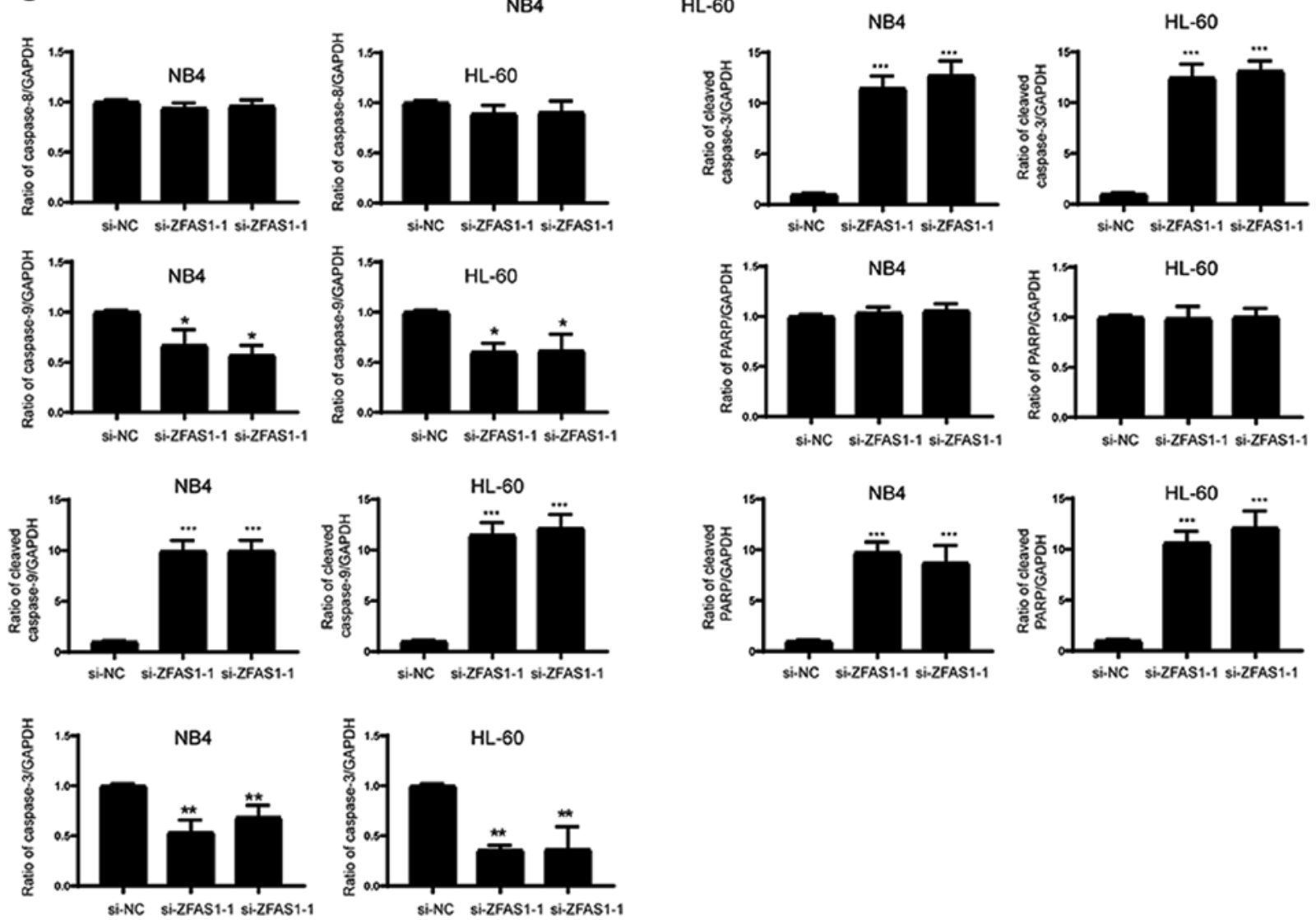

Figure 4. Knockdown of ZFAS1 induces apoptosis in APL cells. (A) Flow cytometry was applied to analyze the apoptotic rate of NB4 and HL-60 cells transfected with si-NC, si-ZFAS1-1 or si-ZFAS1-2 for $48 \mathrm{~h}$. (B) Western blot analyses of indicated proteins in APL cells transfected with si-NC, si-ZFAS1-1 or si-ZFAS1-2 for $48 \mathrm{~h}$. (C) Densities of the bands in (B) were quantified by densitometry using Bio-Rad Quantity One software. Values are presented as the mean \pm standard deviation $(\mathrm{n}=3) .{ }^{*} \mathrm{P}<0.05,{ }^{* *} \mathrm{P}<0.01$ and ${ }^{* * * *} \mathrm{P}<0.001$. ZFAS1, long non-coding RNA zinc finger antisense 1; APL, acute promyelocytic leukemia; si-, small interfering RNA; NC, negative control; GAPDH, glyceraldehyde 3-phosphate dehydrogenase; PARP, poly ADP ribose polymerase. 

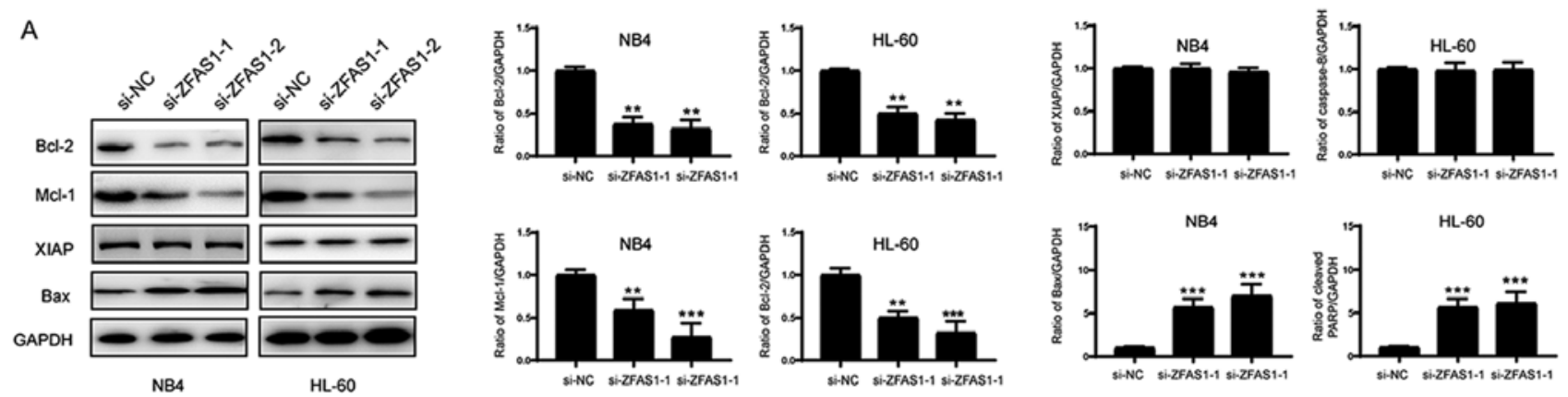
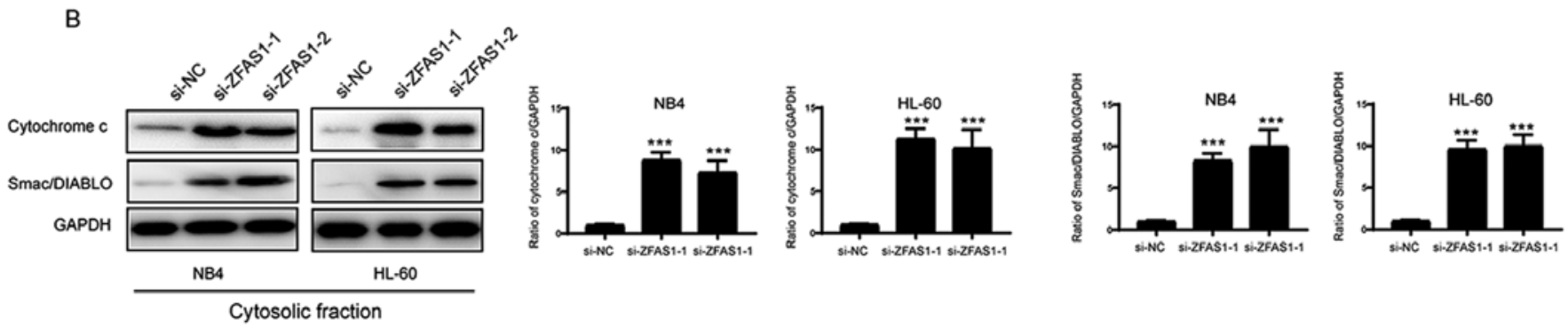

Figure 5. ZFAS1 regulates APL cell apoptosis through the modulation of Bcl-2 family proteins. (A) APL cells were transfected with si-NC, si-ZFAS1-1 or si-ZFAS1-2 for $48 \mathrm{~h}$. The levels of Bcl-2, Mcl-1, XIAP and Bax were examined by western blot analyses with the indicated antibodies. Densitometry analysis of the western blots is presented on the right. ${ }^{* *} \mathrm{P}<0.01,{ }^{* * * *} \mathrm{P}<0.001$ vs. si-NC. (B) APL cells were transfected with si-NC, si-ZFAS1-1 or si-ZFAS1-2 for $48 \mathrm{~h}$. Cytosolic fractions were subjected to western blotting with the indicated antibodies and densitometry analysis is presented on the right. ${ }^{* * *} \mathrm{P}<0.001$ vs. si-NC. Values are presented as the mean \pm standard deviation $(n=3)$. ZFAS1, long non-coding RNA zinc finger antisense 1; APL, acute promyelocytic leukemia; si- small interfering RNA; NC, negative control; GAPDH, glyceraldehyde 3-phosphate dehydrogenase; Bcl-2, B-cell lymphoma-2; Mcl-1, induced myeloid leukemia cell differentiation protein Mcl-1; XIAP, E3 ubiquitin-protein ligase XIAP; Bax, apoptosis regulator BAX; Smac/DIABLO, Diablo homolog mitochondrial.

The present data showed that the expression of the lncRNA ZFAS1 is significantly upregulated in APL patients compared with that in healthy controls. The lncRNA ZFAS1 has previously been found to be dysregulated in several different cancer types. For example, ZFAS1 is overexpressed in gastric cancer and its increased level is associated with a poor prognosis and shorter survival times (25). ZFAS1 also promotes metastasis and is associated with a poor prognosis in hepatocellular carcinoma (13). However, ZFAS1 expression is decreased in breast tumors and functions as a tumor suppressor gene in breast cancer (12). The discrepancy with regard to the function of ZFAS1 may be due to the different cancer type. Currently, the role of ZFAS1 in APL remains unknown. The present study data showed that ZFAS1 expression was significantly increased in APL samples compared with that in healthy samples, indicating that ZFAS1 may serve an important role in the development and progression of APL. Moreover, silencing of ZFAS1 by RNAi lead to the marked inhibition of APL cell proliferation. In addition, an Annexin V/PI staining assay showed that the downregulation of ZFAS1 repressed APL cell proliferation by inducing apoptosis.

Apoptosis is a programmed cellular death mechanism that is initiated by two pathways: The extrinsic and intrinsic pathways. In the present study, subsequent to downregulating ZFAS1, increased cleaved caspase-3 and caspase-9, and PARP was detected, while caspase- 8 was not affected. Therefore, ZFAS1 appears to regulate apoptosis via the intrinsic pathway rather than the extrinsic pathway. It is well documented that the intrinsic pathway is mainly mediated by the $\mathrm{Bcl}-2$ protein family, which controls the stability of the mitochondrial membrane (6). Among the $\mathrm{Bcl}-2$ protein family members, Bcl-2, Mcl-2 and Bcl2-associated agonist of cell death (Bcl-xl) are all upregulated in numerous types of tumor (26). Bax and Bcl-2 homologous antagonist/killer (Bak) are involved in the formation of pores in the outer mitochondrial membrane and the release of cytochrome $c$ and Smac/DIABLO. Together, these steps finally lead to the activation of caspase-3 $(27,28)$. A number of studies have shown that IncRNAs affect the levels of Bcl-2 family proteins (29). For example, the knockdown of hepatocellular carcinoma upregulated lncRNA is able to inhibit $\mathrm{Bcl}-2$, thereby promoting apoptosis in diffuse large B-cell lymphoma (30). The lncRNA CDKN2B antisense RNA 1, which is found to be upregulated in bladder cancer, serves as a positive regulator of $\mathrm{Bcl}-2$ and a negative regulator of Bax (31). Similarly, silencing of ZFAS1 reduced the levels of Bcl-2, Mcl-1, and increased the levels of Bax, cytochrome $c$ and Smac/DIABLO. These data confirm that ZFAS1 regulates APL cell apoptosis through modulation of Bcl-2 protein family members and the intrinsic pathway.

To the best of our knowledge, the present study is the first to show that the IncRNA ZFAS1 regulates proliferation as well as apoptosis in APL cells. Taken together, the results showed that ZFAS1 was highly upregulated in samples from APL patients, and affected APL cell proliferation and apoptosis in vitro. The present study highlights the importance of the largely unexplored population of non-protein-coding genes in understanding the molecular basis of disease, and may provide 
a potential biomarker and therapeutic target for the clinical management of APL.

\section{Acknowledgements}

Not applicable.

\section{Funding}

No funding was received.

\section{Availability of data and materials}

The datasets used and/or analyzed during the current study are available from the corresponding author on reasonable request.

\section{Authors' contributions}

LS performed the cell culture, cell transfection, western blotting and RT-qPCR. HK repeated the experiments and drafted the first version of manuscript. FW performed the cell viability assays. HL performed the flow cytometry analysis. WW performed the cell culture experiments and collected the clinical data. GW, XY and JW performed the cell culture experiments. QF designed the experiment and revised the final version of the manuscript.

\section{Ethics approval and consent to participate}

The study was approved by the Ethics Committee of the First Affiliated Hospital, School of Medicine, Zhejiang University (Hangzhou, China). All procedures that involved human participants were in accordance with the Ethical Standards of The National Research Committee and with the 1964 Declaration of Helsinki and following amendments. Written informed consent was obtained from all study participants.

\section{Patient consent for publication}

Not applicable.

\section{Competing interests}

The authors declare that they have no competing interests.

\section{References}

1. He Y, Meng XM, Huang C, Wu BM, Zhang L, Lv XW and Li J: Long noncoding RNAs: Novel insights into hepatocelluar carcinoma. Cancer Lett 344: 20-27, 2014.

2. Testa U and Lo-Coco F: Prognostic factors in acute promyelocytic leukemia: Strategies to define high-risk patients. Ann Hematol 95: 673-680, 2016.

3. Wilusz JE, Sunwoo H and Spector DL: Long noncoding RNAs: Functional surprises from the RNA world. Genes Dev 23: 1494-1504, 2009.

4. Gutschner T and Diederichs S: The hallmarks of cancer: A long non-coding RNA point of view. RNA Biol 9: 703-719, 2012.

5. Carninci P, Kasukawa T, Katayama S, Gough J, Frith MC Maeda N, Oyama R, Ravasi T, Lenhard B, Wells C, et al: The transcriptional landscape of the mammalian genome. Science 309: 1559-1563, 2005.

6. Mercer TR, Dinger ME and Mattick JS: Long non-coding RNAs: Insights into functions. Nat Rev Genet 10: 155-159, 2009.
7. Kogo R, Shimamura T, Mimori K, Kawahara K, Imoto S, Sudo T, Tanaka F, Shibata K, Suzuki A, Komune S, et al: Long noncoding RNA HOTAIR regulates polycomb-dependent chromatin modification and is associated with poor prognosis in colorectal cancers. Cancer Res 71: 6320-6326, 2011.

8. Mourtada-Maarabouni M, Pickard MR, Hedge VL, Farzaneh F and Williams GT: GAS5, a non-protein-coding RNA, controls apoptosis and is downregulated in breast cancer. Oncogene 28: 195-208, 2009.

9. Benetatos L, Vartholomatos G and Hatzimichael E: MEG3 imprinted gene contribution in tumorigenesis. Int J Cancer 129: 773-779, 2011.

10. Gutschner T, Hämmerle M, Eissmann M, Hsu J, Kim Y, Hung G, Revenko A, Arun G, Stentrup M, Gross M, et al: The noncoding RNA MALAT1 is a critical regulator of the metastasis phenotype of lung cancer cells. Cancer Res 73: 1180-1189, 2013.

11. Svoboda M, Slyskova J, Schneiderova M, Makovicky P, Bielik L, Levy M, Lipska L, Hemmelova B, Kala Z, Protivankova M, et al: HOTAIR long non-coding RNA is a negative prognostic factor not only in primary tumors, but also in the blood of colorectal cancer patients. Carcinogenesis 35: 1510-1515, 2014.

12. Askarian-Amiri ME, Crawford J, French JD, Smart CE, Smith MA, Clark MB, Ru K, Mercer TR, Thompson ER, Lakhani SR, et al: SNORD-host RNA Zfas1 is a regulator of mammary development and a potential marker for breast cancer. RNA 17: 878-891, 2011.

13. Li T, Xie J, Shen C, Cheng D, Shi Y, Wu Z, Deng X, Chen H, Shen B, Peng C, et al: Amplification of long noncoding RNA ZFAS1 promotes metastasis in hepatocellular carcinoma. Cancer Res 75: 3181-3191, 2015

14. Thorenoor N, Faltejskova-Vychytilova P, Hombach S, Mlcochova J, Kretz M, Svoboda M and Slaby O: Long non-coding RNA ZFAS1 interacts with CDK1 and is involved in p53-dependent cell cycle control and apoptosis in colorectal cancer. Oncotarget 7: 622-637, 2016.

15. Zeng C, Xu Y, Xu L, Yu X, Cheng J, Yang L, Chen S and Li Y: Inhibition of long non-coding RNA NEAT1 impairs myeloid differentiation in acute promyelocytic leukemia cells. BMC Cancer 14: 693, 2014.

16. Zeng C, Yu X, Lai J, Yang L, Chen S and Li Y: Overexpression of the long non-coding RNA PVT1 is correlated with leukemic cell proliferation in acute promyelocytic leukemia. J Hematol Oncol 8: 126, 2015.

17. English D and Andersen BR: Single-step separation of red blood cells. Granulocytes and mononuclear leukocytes on discontinuous density gradients of Ficoll-Hypaque. J Immunol Methods 5: 249-252, 1974.

18. Fuss IJ, Kanof ME, Smith PD and Zola H: Isolation of whole mononuclear cells from peripheral blood and cord blood. Curr Protoc Immunol Chapter 7: Unit 7.1, 2009.

19. Livak KJ and Schmittgen TD: Analysis of relative gene expression data using real-time quantitative PCR and the 2(-Delta Delta C(T)) method. Methods 25: 402-408, 2001.

20. Lanotte M, Martin-Thouvenin V, Najman S, Balerini P, Valensi F and Berger R: NB4, a maturation inducible cell line with $\mathrm{t}(15 ; 17)$ marker isolated from a human acute promyelocytic leukemia (M3). Blood 77: 1080-1086, 1991.

21. Dimberg A and Oberg F: Retinoic acid-induced cell cycle arrest of human myeloid cell lines. Leuk Lymphoma 44: 1641-1650, 2003.

22. Dimberg A, Bahram F, Karlberg I, Larsson LG, Nilsson K and Oberg F: Retinoic acid-induced cell cycle arrest of human myeloid cell lines is associated with sequential down-regulation of c-Myc and cyclin E and posttranscriptional up-regulation of p27(Kip1). Blood 99: 2199-2206, 2002.

23. Galluzzi L, López-Soto A, Kumar S and Kroemer G: Caspases connect cell-death signaling to organismal homeostasis. Immunity 44: 221-231, 2016.

24. Adams J and Nassiri M: Acute promyelocytic leukemia: A review and discussion of variant translocations. Arch Pathol Lab Med 139: 1308-1313, 2015.

25. Nie F, Yu X, Huang M, Wang Y, Xie M, Ma H, Wang Z, De W and Sun M: Long noncoding RNA ZFAS1 promotes gastric cancer cells proliferation by epigenetically repressing KLF2 and NKD2 expression. Oncotarget 8: 38227-38238, 2017.

26. Yu R, Yu BX, Chen JF, Lv XY, Yan ZJ, Chen Y and Ma Q: Anti-tumor effects of Atractylenolide I on bladder cancer cells. J Exp Clin Cancer Res 35: 40, 2016. 
27. Delbridge AR and Strasser A: The BCL-2 protein family, BH3-mimetics and cancer therapy. Cell Death Differ 22: 1071-1080, 2015

28. Martinou JC and Youle RJ: Mitochondria in apoptosis: Bcl-2 family members and mitochondrial dynamics. Dev Cell 21: 92-101, 2011

29. Gross A, McDonnell JM and Korsmeyer SJ: BCL-2 family members and the mitochondria in apoptosis. Genes Dev 13: 1899-1911, 1999.

30. Peng $\mathrm{W}, \mathrm{Wu} \mathrm{J}$ and Feng J: Long noncoding RNA HULC predicts poor clinical outcome and represents pro-oncogenic activity in diffuse large B-cell lymphoma. Biomed Pharmacother 79: 188-193, 2016.
31. Zhu H, Li X, Song Y, Zhang P, Xiao Y and Xing Y: Long non-coding RNA ANRIL is up-regulated in bladder cancer and regulates bladder cancer cell proliferation and apoptosis through the intrinsic pathway. Biochem Biophys Res Commun 467: 223-228, 2015 .

(i) () () This work is licensed under a Creative Commons Attribution-NonCommercial-NoDerivatives 4.0 International (CC BY-NC-ND 4.0) License. 